\title{
Natural Zeolite Catalyst for Conversion of $\alpha$-Pinene
}

\author{
Wijayati N. and Utomo A. B.
}

\begin{abstract}
The Natural zeolite catalyst $(\mathrm{Si} / \mathrm{Al}=2.5)$ was prepared by calsination. The physico-chemical properties were investigated by XRD, ${ }^{29} \mathrm{Si}$ MAS NMR, SEM, GC-MS and FT-IR spectroscopy of pyridine adsorbed. The activity of test of these catalysts has been carried out over the liquid-phase conversion of $\alpha$-pinene. The converson reaction with natural zeolite, the highest selectivity of terpin compound was $59.08 \%$ with a conversion of $99.78 \%$ at 120 min.
\end{abstract}

Index Terms-Natural zeolite, $\alpha-$ Pinene, conversion.

\section{INTRODUCTION}

Zeolite material is available so much in Indonesia because most areas in Indonesia are volcanic mountain, which is source of Zeolite minerals. According to the geologist's research, there has been found 47 location of zeolites mining in Indonesia, the three are in East Java is Sumbermanjing-Wetan, Kedung Banteng village and Sumber Agung village in South Malang and Slaung Ponorogo, approximately have million tons stocks.

Zeolites are natural or synthetic crystalline, microporous, aluminosilicate materials with structures consisting of three dimensional frameworks of $\mathrm{SiO}_{4}$ and $\mathrm{AlO}_{4}$ tetrahedra linked through oxygen bridges [1]. Zeolite solid acidity make it useful as ion exchange, adsorption, heterogeneous catalysis, biosorption supports, polymer catalytic degradation and also attract interest in materials science for the development of functional materials and in nanotechnology [2]-[5].

The conversion reaction of $\alpha$-pinene in the presence of zeolite catalyst has been well studied, and intensely so in the last ten years. Mochida et al. [7] reported the use of zeolites and obtained $100 \%$ conversion, but with low selectivity for alcohols (around 57\%).

The wealth of experimental material has attracted the attention of theoricians for decades. The whole spectrum of intrazeolite phenomema such as 1) diffusion of reactans into the zeolite, 2) physisorption (chemisorption) at the active site, 3 ) reaction of the conversion, 4) desorption, and 5) diffusion out of the zeolite [8].

Based on the statement above, the use of zeolite because of the big enough relatively of adsorption capacity and state use in cattle raising ang medical. So that need the development of the use of zeolite as new adsorbent raw material. This paper describes the characterization of the natural zeolite catalyst and the use in the conversion of $\alpha$-pinene as catalyst.

Manuscript received March 26, 2015; revised June 25, 2015.

Wijayati N. is with the Department of Chemistry, State University of Semarang, Jl. Raya Sekaran Gunungpati Semarang, 50229, Indonesia (e-mail: nanikanang@gmail.com; tel.: +6281575579586).

Utomo A. B. is with STIFAR, "Yayasan Pharmasi", Jl.Letjen Sarwo Edhi Wibowo Km 1, Plamongansari, Semarang, Indonesia.

\section{Procedure}

\section{A. Experimetal}

The catalysts were characterized by XRD, ${ }^{29} \mathrm{Si}$ MAS NMR, SEM, GC-MS and FT-IR spectroscopy of pyridine adsorbed. $\mathrm{X}$-Ray Diffractometer (D-Max III (Rigaku), radiation $\mathrm{Cu} \mathrm{K \alpha}$ $(\alpha=1.5378 \mathrm{~A}, 40 \mathrm{kV}, 30 \mathrm{~mA})$. The NMR spectra were obtained at $9.4 \mathrm{~T}$ on a Bruker DRX-400 spectrometer using $4 \mathrm{~mm} \mathrm{ZrO}_{2}$ rotors at room temperature. ${ }^{29} \mathrm{Si}$ MAS NMR spectra with high power proton decoupling was obtained at $79.49 \mathrm{MHz}$ with a spinning rate of $12 \mathrm{kHz}$, pulse length of 3 mikros and a recycle time of $20 \mathrm{s.} 4 \mathrm{~mm}$ rotors was used and the ${ }^{29} \mathrm{Si}$ chemical shifts was repored relative to TMS. The morphology and mean crystallite size of the zeolites was determined by scanning electron microscopy (SEM) in a JEOL JFC-1600 and JSM-6701F equipment. 1) Pt auto fine coater, Model: JEOL JFC-1600; Parameters: 20mA, 30sec coating time; Pt thickness: approx. $5 \mathrm{~nm}$. 2) FESEM. Model: JEOL JSM-6701F Voltage range: 0.1 - 30kV, Magnification: 25X-650kX, Resolution: $1 \mathrm{~nm}$ by specification. The IR spectroscopy of pyridine adsorbed (Py-IR) was carried out on a (Hitachi 270-50; Perkin Elmer Paragon 1000 PC; Shimadzhu FTIR-8201PC). GC-MS instrument (Agilent GC/MSD (7890A/5975C). The column used was DB-5MS $27 \mathrm{~m} \times 0.25 \mathrm{~mm} \times 0.25 \mathrm{um}$ B-5, Mass range: 41-500amu, Carrier gas flow rate: $1 \mathrm{ml} / \mathrm{min}$, Injector temperature: $260^{\circ} \mathrm{C}$; Temperature program: $50^{\circ} \mathrm{C}(2 \mathrm{~min})-260^{\circ} \mathrm{C}(5 \mathrm{~min})$, heating rate $5^{\circ} \mathrm{C} / \mathrm{min}$; Flow: $1 \mathrm{~mL} / \mathrm{min}$; split ratio: 20 . Note: $3 \mathrm{uL}$ of sample TP diluted with $1 \mathrm{~mL}$ of methanol for GCMS analysis.

\section{B. Praparation of Catalyst}

Natural zeolite was calcined by flowing nitrogen, oxidized by oxygen, and reduced by hydrogen gasses. Characterizations of catalysts including acidity test, determination of crystallinity, and metal content were carried out respectively by using pyridine adsorption, XRD, SEM and ${ }^{29} \mathrm{Si}$ MAS NMR.

\section{Catalitic Test}

Acid catalyzed hydration reaction of $\alpha$-pinene was conducted using bath reactor of $100 \mathrm{~mL}$ three-neck flask with condenser, a sample and a thermometer. A mixture of 1.84 mmol of $\alpha$-pinene, $2.5 \mathrm{~mL}$ of $\mathrm{H}_{2} \mathrm{O}$, and $3.4 \mathrm{~mL}$ of isopropyl alcohol was loaded into reactor. The mixture was stirred and warmed up to the desired temperature. Once the desired temperature was reached, the $400 \mathrm{mg}$ of natural zeolite catalyst was added into the reactor. The reaction products were analyzed by GC by taking samples at $30,60,120$, and $240 \mathrm{~min}$ after the addition of catalyst. The samples were centrifuged at high speed of rotation (350 rpm) for about 10 $\mathrm{min}$ at ambient temperature to ensure that they were free of solid catalyst. Peak identification of the products was done by GC-MS analysis. 


\section{RESULT AND DISCUSSION}

\section{A. Acidity Test of Natural Zeolite Catalyst}

Acidity test was conducted by ammonia and pyridine adsorption. Ammonia and pyridine were chosen as adsorbates because they are small molecules allowing them to be adsorbed not only on the surface but also in the zeolite channels. In addition, ammonia can also act as Lewis and Brønsted bases so that the total acidity can be determined well. Determination of acidity of the catalyst with pyridine used to determine the Lewis acid sites only, because pyridine can only act as a Lewis acid alone (see Fig. 1).

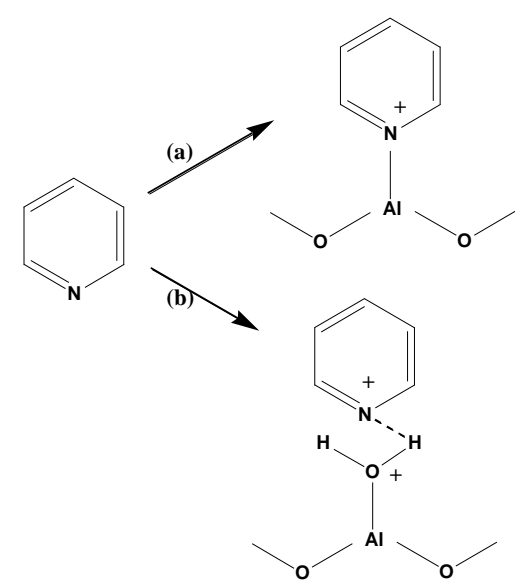

Fig. 1. Interaction of pyridine (a) Lewis dan; (b) BrØnsted acid sites from natural zeolite catalyst.

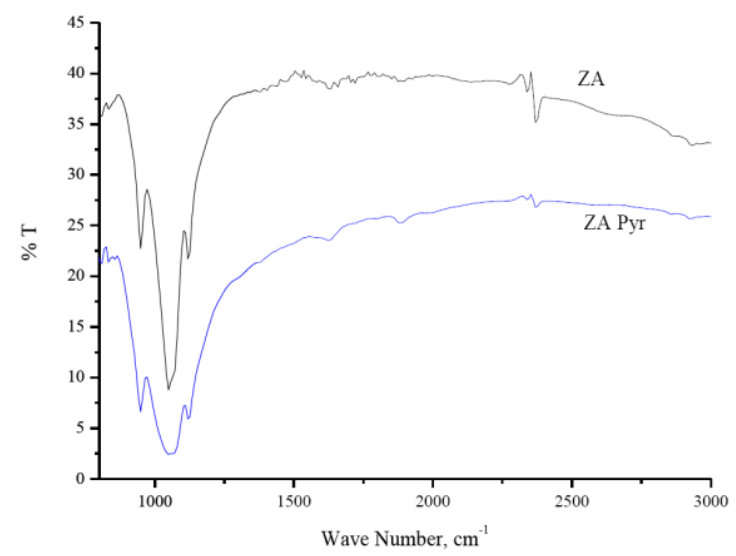

Fig. 2. FT-IR spectra of natural zeolite.

\section{B. FT-IR Analysis}

The amount of Brønsted and Lewis acid sites of the studied samples, as determined by pyridine adsorption (Py-IR), are shown in Fig. 2. Py-IR spectra of two characteristic absorption peaks, of which $1543 \mathrm{~cm}^{-1}$ and $1442 \mathrm{~cm}^{-1}$, attributable to pyridine adsorbed on Brönsted acid and Lewis acid sites, respectively [11], [12].

\section{XRD}

The X-ray powder diffraction (XRD) patterns of natural zeolite was shown in Fig. 3. The XRD patterns show that the sample was zeolites topology, well crystallined and are free from impurities. The result show that zeolite mining rock Malang, contains kinds of Mordenite.

\section{D. ${ }^{29}$ Si MAS (Majic Angle Spinning) NMR}

The ${ }^{29} \mathrm{Si}$ MAS NMR spectra of the natural zeolite samples are shown in Fig. 4. It is well known that a ${ }^{29} \mathrm{Si}$ MAS NMR spectrum of the natural zeolite may contain up to five lines depending on the number of aluminum atoms and silanol groups connected to the silicon atom [9], [10]. The ${ }^{29} \mathrm{Si}$ MAS NMR spectrum of the natural zeolite sample shows the presence of four components, corresponding to $\mathrm{Si}(0 \mathrm{Al})$, $\mathrm{Si}(1 \mathrm{Al}), \mathrm{Si}(2 \mathrm{Al})$ and $\mathrm{Si}(3 \mathrm{Al})$ species at $-108,-102,-99$, and -94 ppm, respectively, similar to that observed by Yan et al., [9].

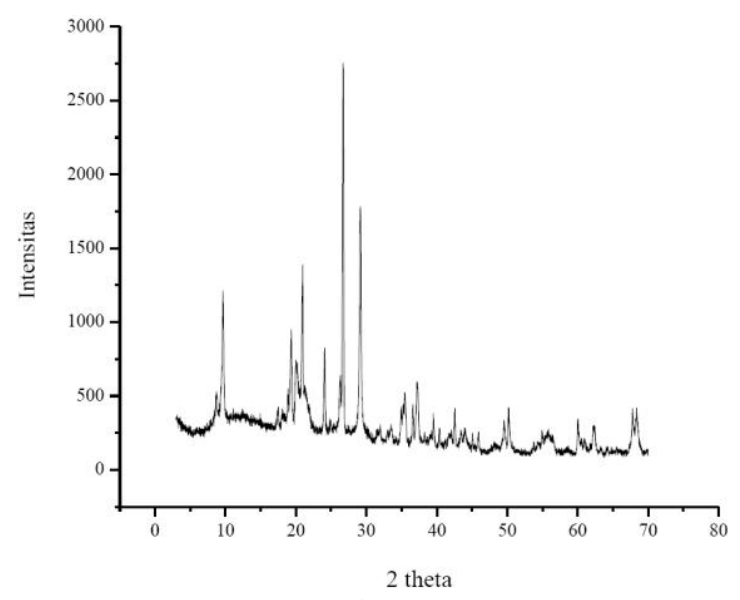

Fig. 3. XRD pattern of natural zeolite catalyst.

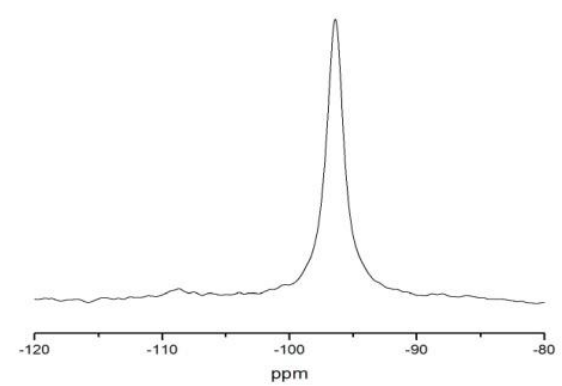

Fig. 4. ${ }^{29}$ Si MAS NMR spectrum of Natural Zeolite.

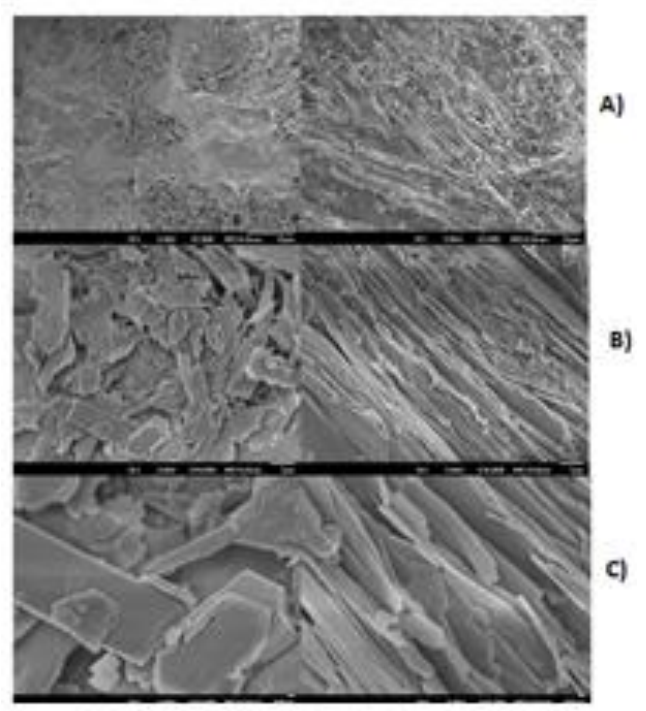

Fig. 5. SEM image of ZA different magnifications (A) $10 \mu \mathrm{m}$, (B) $1 \mu \mathrm{m}$, and (C) $100 \mathrm{~nm}$.

\section{E. SEM}

Scanning electron microscopy (SEM) concludes that the morphology of the outer surface of the natural zeolite crystals (see Fig. 5).

\section{F. Catalytic Acivity}

Catalytic study was performed using natural zeolite. The 
molecular size of $\alpha$-pinene was estimated to be $0.62 \times 0.59 \times$ $0.53 \mathrm{~nm}$, which is smaller than natural zeolite catalysts [7]. The reaction was carried out in an excess of water with $\alpha$-pinene as the limiting reagent. $\alpha$-Pinene was almost immiscible in water at the reaction conditions. It forms a separated organic phase in the reactor. The reaction taken place over the catalyst surrounded by the aqueous phase. $\alpha$-Pinene should adsorb on acid site to promote the acid catalyzed reaction the presence of water [13].

Effect of reaction time on the $\alpha$-pinene conversion and selectivity of product for natural zeolite catalyst was shown in Fig. 6.

To achieve a well mixing between the reagents and the $\alpha$-pinene during reaction, they must be stirred well at constant rate. The observed conversion of $\alpha$-pinene with natural zeolite was observed at from $30 \mathrm{~min}$ until $240 \mathrm{~min}$. The highest selectivity of terpin compound was $59.08 \%$ with a conversion of $99.78 \%$ at $120 \mathrm{~min}$.

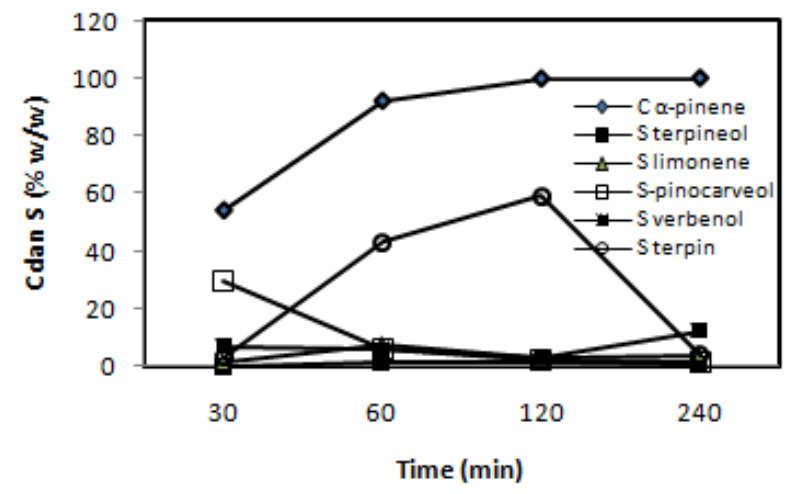

Fig. 6. Conversion and selectivity of product vs. reaction time. $\mathrm{S}=$ Selectivity $; \mathrm{C}=$ Conversion

Fig. 6 shows that the main products were $\alpha$-terpineol, limonene, pinocarveol, verbenol, and terpin. Castanheiro, et al. [13] proposed reaction scheme for the acid catalyzed conversion of $\alpha$-and $\beta$-pinene. They used molybdophosphoric acid as catalyst and obtained limonene, $\alpha$-terpineol and terpin as main products. This selectivity (Fig. 7) consists of a subtle matching of the size and shape of reactans, transitions states and products with the zeolite framework [14].

\section{Reactant Shape SELECTIVITY}

The acid catalyzed the conversion reaction of alkenes in aqueous solution. The acid transfers a proton to double bond of the alkene forming an intermediate of carbocation. The carbocation can lose a proton and generate monocyclic and bicyclic hydrocarbons or, in the presence of a nucleophile, give to monocyclic alcohol. In the conversion of terpenes, variation products might be obtained depending on the catalyst and reaction conditions [6]-[13].

The catalyst of natural zeolite was studied for this conversion reaction. The internal surface of catalyst being highly hydrophobic possesses affinity towards non polar molecules like that of $\alpha$-pinene [7]. Natural zeolite high activity for $\alpha$-pinene conversion, indicating the high potential of this catalyst as an alternative solid acid catalyst to conventional homogeneous catalyst. By evaluating this work, was a good candidate for the industrial conversion of $\alpha$-pinene, due to its easy separation from reaction products and low cost.

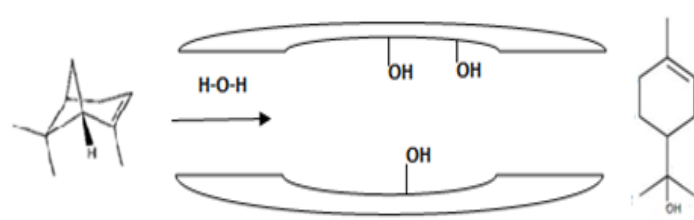

Restricted transition state shape selectivity
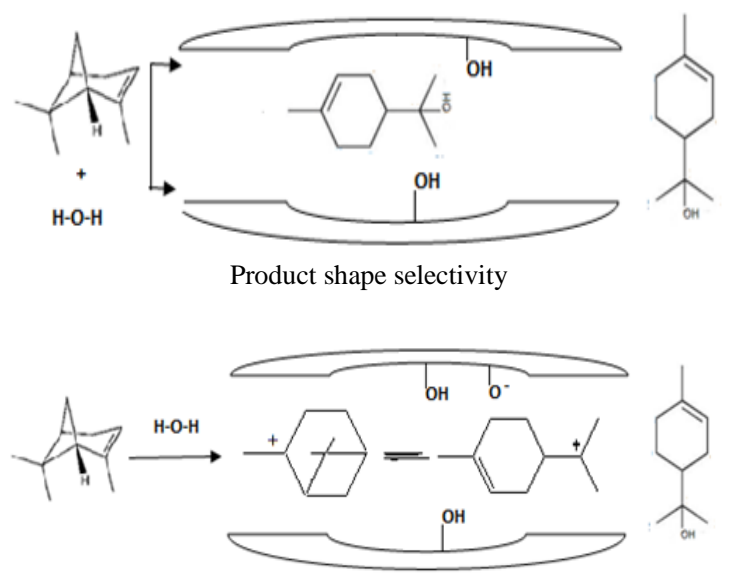

Fig. 7. The three classic types of shape selectivity.

\section{CONCLUSION}

XRD and SEM show that the natural zeolite nanocrystals obtained are highly crystalline, contains kinds of Mordenite. $\mathrm{The} \mathrm{Si} / \mathrm{Al}$ ratio of natural zeolite was 2.5 . The natural zeolite was a good candidate for the industrial conversion of $\alpha$-pinene, due to its easy separation from reaction products and low cost. The conversion of $\alpha$-pinene catalyzed by natural zeolite was fast and leads mainly to terpin as the major product (up to $59 \%$ ).

\section{ACKNOWLEDGMENT}

The authors would like to thank Directorate General of Higher Education (DGHE), Department of National Education Republic Indonesia for to support. The authors thank to, Department of Chemistry, Faculty of Science, National University of Singapore (NUS) for assistance with sample characterization.

\section{REFERENCES}

[1] B. Silva, H. Figueiredo, O. S. G. P. Soares, M. F. R. Pereira, J. L. Figueiredo, A. E. Lewandowska et al., "Evaluation of ion exchange-modified Y and ZSM5 zeolites in $\mathrm{Cr}(\mathrm{VI})$ biosorption and catalytic oxidation of ethyl acetate," Appl. Catal. B- Environ., pp. 117-118, 406-413, 2012.

[2] H. Su, H. S. Kim, S. M. Seo, S. O. Ko, J. M. Suh, G. H. Kim, and W. T. Lim, "Location of $\mathrm{Na}+$ ions in fully dehydrated $\mathrm{Na}^{+}$-saturated zeolite $\mathrm{Y}$ (FAU, Si/Al = 1.56)," Bull. Korean Chem. Soc., vol. 33, no. 8, p. 2785 , 2012.

[3] C. K. Modi and P. M. Trivedi, "Synthesis, characterization and catalytic behaviour of entrapped transition metal complexes into the zeolite Y," Adv. Mat. Lett., vol. 3, no. 2, pp.149-153, 2012.

[4] C. J. A. Mota and N. Rosenbach Jr., "Carbocations on zeolites. Quo vadis?” J. Braz. Chem. Soc., vol. 22, no. 7, pp. 1197-1205, 2011. 
[5] Y. Zheng, X. Li, and P. K. Dutta, "Exploitation of unique properties of zeolites in the development of gas sensors," Sensors, vol. 12, pp. 5170-5194, 2012.

[6] M. C. Avila, A. Nora, E. Cornelli, Rodriguez-Castellon, and A. Jimenez-Lopez, "Study of solid acid catalysis for the conversion of a-pinene," J. Mol. Catal. A-Chem., vol. 322, no. 1-2, pp. 106-112, 2010.

[7] T. Mochida, O. Ryuichiro, H. Naoto, K. Yuichi, and O. Toshio, "Conversion of $\alpha$-pinene over hydrophobic zeolites in 1,4-dioxane-water and in water," Micropor. Mesopor. Mat., vol. 101, pp. 176-183, 2007.

[8] L. Benco, T. Demuth, and F. Hutschka, "Catalytic conversion of hydrocarbons in zeolites from first principles," Pure Appl. Chem., vol. 74, no. 11, p. 2097, 2002.

[9] Z. Yan, D. Ma, J. Zhuang, X. Liu, X. Liu, X. Han, X. Bao, F. Chang, L. $\mathrm{Xu}$, and Z. Liu, "On the acid-dealumination of USY zeolite: a solid state NMR investigation," J. Mol. Catal. A-Chem., vol. 194, pp. 153-167. 2003.

[10] J. Jiao, W. Wang, B. Sulikowski, J. Weitkamp, and M. Hunger, ${ }^{، 29} \mathrm{Si}$ and ${ }^{27} \mathrm{Al}$ MAS NMR characterization of non-hydrated zeolites $\mathrm{Y}$ upon adsorption of ammonia," Micropor. Mesopor. Mat., vol. 90, pp. 246-250. 2006

[11] K. Suzuki, T. Noda, N. Katada, and M. Niwa, "IRMS-TPD of ammonia: Direct and individual measurement of Brønsted acidity in zeolites and its relationship with the catalytic cracking activity," J. Catal., vol. 250, pp. 151-160. 2007.

[12] C. K. Modi and P. M. Trivedi, "Synthesis, characterization and catalytic behaviour of entrapped transition metal complexes into the zeolite Y,” Adv. Mat. Lett., vol. 3, no, 2, pp.149-153, 2012.
[13] J. E. Castanheiro, I. M. Foseseca, A. M. Ramos, R. Oliveira, and J. Vital, "Conversion of $\alpha$-pinene over molybdophosphoric aced immobilized in hydrophobically modified PVA membranes," Catal. Today, vol. 104, pp. 296-304. 2005.

[14] M. Wallau and U. Schuchardt, "Catalysis by Metal Containing Zeolites. I: Basic Sites," J. Braz.Chem. Soc., vol. 4, no. 4, pp. 393-403,1995.

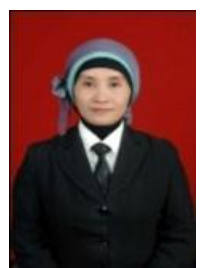

Wijayati N. was born in Blora, Central Java, Indonesia on October 23, 1969. She received her doctoral degree in organic chemistry from the Universitas Gadjah Mada, Indonesia. Her area of interest is in organic reaction using homogeneoues and heterogeneous catalysts.

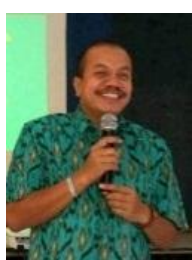

Utomo A. B. was born in Semarang, Central Java in Indonesia on February 9, 1969. His area of interest is in organic reaction and pharmation product. 